\title{
Changes of the extracellular matrix of the cornea in diabetes mellitus
}

\author{
Annette Hager
}

Received: 3 October 2009 / Accepted: 5 October 2009 /Published online: 25 October 2009

(C) Springer-Verlag 2009

\section{Dear Editor,}

We are aware of the discrepancy between the results of a significantly higher corneal hysteresis $(\mathrm{CH})$ in diabetic patients $[1,2]$ and the effect of collagen cross linking by diabetes that may be expected to lower $\mathrm{CH}$ as shown by other authors [3].

In our rather large group of patients, $\mathrm{CH}$ was higher in diabetes when corrected for age and possible other cofounders such as glaucoma, refraction, gender, side of the eye and IOP as measured by Goldmann applanation tonometry [1]. In linear mixed model analysis, we found that age, IOP and diabetes have a significant influence on $\mathrm{CH}$. These effects, however, are shown to influence $\mathrm{CH}$ in opposite directions, so that they need to be taken into consideration when comparing $\mathrm{CH}$ in normal eyes and eyes of diabetic patients.

We pointed out that the effect of age as well as the effect of diabetes-induced cross linking of collagen fibrils was expected to lower $\mathrm{CH}$. This effect can clearly be shown for age, and was taken into consideration in multivariate analysis. Since $\mathrm{CH}$ was significantly higher in diabetes after correcting for age (and this seems to be essential since diabetes Type II is a disease of the elderly) and IOP, we assume structural alterations of the matrix proteoglycans modifying corneal viscosity and therefore increasing $\mathrm{CH}$.

It would be very interesting if data from Bayer et al. were evaluated comparing $\mathrm{CH}$ values in normal and diabetic eyes after correcting for age and IOP.

While $\mathrm{CH}$ is a parameter that is measured primarily using the ORA instrument, corneal resistance factor (CRF) is derived from $\mathrm{CH}$ measurement [4].

\footnotetext{
A. Hager $(\bowtie)$

Department of Ophthalmology,

Tangstedter Landstr. 400,

22415 Hamburg, Germany

e-mail: anhager@gmx.de
}

According to Luce the formula is $\mathrm{CRF}=\mathrm{P} 1-\mathrm{k} \times \mathrm{P} 2$ with $\mathrm{k}$ being an empirical constant.

So far, we have only little experience with the different pieces of information about rigidity and/or elasticity of the cornea given by $\mathrm{CH}$ and $\mathrm{CRF}$ [5]. We wanted to evaluate the impact of the $\mathrm{CH}$ measurement first [5].

Congdon et al. [6] described lower $\mathrm{CH}$ values to be a risk factor in glaucoma patients for further progression of visual field deterioration. Therefore, higher $\mathrm{CH}$ might suggest a protective function in glaucoma which might be an advantage for diabetic patients.

To date, cross-sectional or longitudinal studies of biomechanical properties of the cornea have been impossible. For the future, we expect quite a few new and interesting findings with regard to the biomechanical properties of the cornea in diabetes.

\section{References}

1. Hager A, Wegscheider K, Wiegand W (2009) Changes of extracellular matrix of the cornea in diabetes mellitus. Graefes Arch Clin Exp Ophthalmol 247(10):1369-1374. doi:10.1007/s00417-009-1088-4

2. Goldich Y, Barkana Y, Gerber Y, Rasko A, Morad Y, Harstein M, Avni I, Zadok D (2009) Effect of diabetes mellitus on biomechanical parameters of the cornea. J Cataract Refract Surg 35:715-719

3. Sahin A, Bayer A, Ozge G, Mumcuoglu T (2009) Corneal biomechanical changes in diabetes mellitus and their influence on intraocular pressure measurements. Invest Ophthalmol Vis Sci 50 (10):4597-4604. doi:iovs.08-2763 (pii)

4. Luce DA (2005) Determining in vivo biomechanical properties of the cornea with an ocular response analyzer. J Cataract Refract Surg $31: 156-162$

5. Spoerl E, Terai N, Haustein M, Böhm AG, Raiskup-Wolf F, Pillunat LE (2009) Biomechanical condition of the cornea as a new indicator for pathological and structural changes. Ophthalmologe 106:512-520

6. Congdon NG, Broman AT, Bandeen-Roche K, Grover D, Quigley HA (2006) Central corneal thickness and corneal hysteresis associated with glaucoma damage. Am J Ophthalmol 141:868-875 